\title{
(2) Noninnocent $\beta$-Diiminate Ligands: Redox Activity of a Bis(alkylimidazole)methane Ligand in Cobalt and Zinc Complexes
}

\author{
Pradip Ghosh, ${ }^{[a]}$ Richard Naastepad, ${ }^{[a]}$ Charl F. Riemersma, ${ }^{[a]}$ Martin Lutz, ${ }^{[b]}$ Marc- \\ Etienne Moret, ${ }^{[a]}$ and Robertus J. M. Klein Gebbink* ${ }^{*[a]}$
}

\begin{abstract}
A new $\beta$-diiminate ligand (the bis(1-methyl-4,5diphenyl- $1 \mathrm{H}$-imidazol-2-yl)methane anion, $\mathrm{BMIM}^{\mathrm{Ph} 2-}$ ) is introduced, in which the ligand framework bears an extended imidazole-based $\pi$-system in conjugation with a formal $\beta$-diketiminates ( $\mathrm{NacNac}$ ) backbone. Bis-ligated transition metal complexes (Co, Zn) featuring this anionic ligand undergo a series of four consecutive single-electron oxidations that are all ligand-based. The singly and doubly oxidized complexes can be synthesized on a preparative scale and have been fully characterized by various spectroscopic techniques. This is in sharp contrast to the corresponding NacNac-based complexes in which only singly oxidized complexes were isolated and characterized. Single crystal X-ray structure determination revealed a correlation between the intra-ligand metrical parameters and the oxidation state of $\mathrm{BMIM}^{\mathrm{Ph2}-}$. These structural changes in the ligand framework make $\mathrm{BMIM}^{\mathrm{Ph} 2-}$ as a perceptible non-innocent ligand in contrast to NacNac type ligands.
\end{abstract}

In recent times, there is a profound interest in the coordination chemistry of redox-active ligands in order to study and facilitate multi-electron processes in chemical transformations. ${ }^{[1-6]}$ Nature often uses redox-active or non-innocent ligands as redox equivalents in enzymatic processes. ${ }^{[7,8]}$ Several classes of redox-active ligands have been designed and ligand-centered redox events have been studied extensively. ${ }^{[1-6,9]}$ Steric and electronic modifications of ligands were shown to have a profound effect on the reactivity of the corresponding metal complexes. ${ }^{[10]}$ The design of redox-active ligands that are able to

[a] Dr. P. Ghosh, R. Naastepad, C. F. Riemersma, Dr. M.-E. Moret,

Prof. Dr. R. J. M. Klein Gebbink

Organic Chemistry and Catalysis

Debye Institute for Nanomaterials Science

Utrecht University (The Netherlands)

E-mail:r.j.m.kleingebbink@uu.nl

[b] Dr. M. Lutz

Crystal and Structural Chemistry

Bijvoet Center for Biomolecular Research

Utrecht University (The Netherlands)

$\square$ Supporting information and the ORCID identification number(s) for the au-

(iD thor(s) of this article can be found under https://doi.org/10.1002/ chem.201701215. participate in multiple-electron transfer processes at low/accessible potentials is of particular interest.

$\beta$-Diketiminates ( $\mathrm{NacNac}^{-}$) represent a class of monoanionic $\mathrm{N}, \mathrm{N}$-chelating ligands (Scheme 1) that have been studied thoroughly for the synthesis of metal complexes. ${ }^{[11-14]}$ The tunable steric parameters and electronic properties of these ligands have been shown to exert a predictable control over the properties of the coordinated metal ion. ${ }^{[15]}$ For most of the complexes, the NacNac ligands are generally considered as stable scaffolds that do not participate in redox processes. ${ }^{[11-15]}$ Accordingly, attention was centered on the redox properties and reactivity of the coordinated metal center, whereas the redox non-innocent properties of these ligands have been less explored. ${ }^{[16]}$ To our knowledge, three literature reports ${ }^{[17-19]}$ detail on the one electron oxidation of a coordinated anionic $\mathrm{NacNac}^{-}$ligand in $\left[\mathrm{M}^{\prime \prime}(\mathrm{NacNac})_{2}\right]$-type complexes to form $\left[\mathrm{M}^{\prime \prime}(\mathrm{NacNac})(\mathrm{NacNac})\right]^{+}(\mathrm{M}=\mathrm{Co}, \mathrm{Ni}$ and $\mathrm{Zn}) . \mathrm{X}$-ray crystal structures of one-electron oxidized $\left[\mathrm{M}(\mathrm{NacNac})(\mathrm{NacNac})^{\circ}\right]^{+}$complexes $(\mathrm{M}=\mathrm{Co}, \mathrm{Ni})$ are known, ${ }^{[18,19]}$ showing that the cobalt complex has a square planar and the nickel complex a tetrahedral geometry.

In general, the intra-ligand distances of redox-active ligands strongly depend on their oxidation state. Thus, it should be possible to determine the change in ligand oxidation state by high-resolution X-ray crystallography. Due to the presence of an odd number of atoms in the $\mathrm{NaCNac}^{-}$ligand backbone (NCCCN), its HOMO is a non-bonding orbital; consequently, there is no significant change in the intra-ligand distances upon oxidation. For this reason the term "hidden non-innocence" has been coined to describe the oxidation chemistry of $\mathrm{NaCNac}^{-}$ligands. ${ }^{[17]}$

The stability of the NacNac $\pi$-radical highly depends on the fine-tuning of both electronic and steric properties of the substituents on the NCCCN backbone. Accordingly, we aimed for a suitable ligand that can stabilize the neutral $\pi$-radical in metal complexes within the context of redox non-innocent ligand chemistry. We have designed a new class of diimine, HBMIM $^{\text {Ph2 }} \quad$ (bis(1-methyl-4,5-diphenyl-1H-imidazol-2-yl)methane), in which two 1-methyl-4,5-diphenyl-1H-imidazole moieties are attached to a central methylene unit (Scheme 1). The phenyl groups are included in the ligand to provide significant steric bulk. In principle, this ligand $\left(\mathrm{HBMIM}^{\mathrm{Ph2}}\right)$ can act as i) a neutral $\mathrm{N}, \mathrm{N}-$ donor ligand $\left.\left(\mathrm{HBMIM}^{\mathrm{Ph} 2}\right), \mathrm{ii}\right)$ a closed-shell monoanionic ligand $\left(\mathrm{BMIM}^{\mathrm{Ph2}-}\right)$, and iii) a neutral $\pi$-radical ligand $\left(\mathrm{BMIM}^{\mathrm{Ph} 2^{\circ}}\right.$ ). The anionic and $\pi$-radical species in the latter cases 


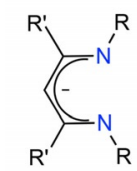

B-diketiminates ( $\mathrm{NacNac}^{-}$)

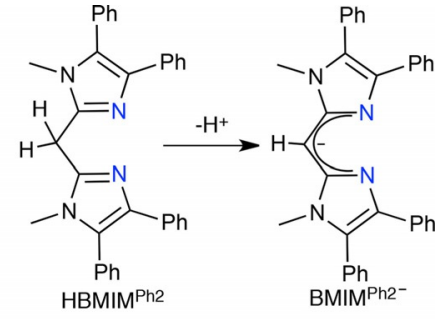

Scheme 1. The $\beta$-diiminate ligand used in this study: HBMIM ${ }^{\mathrm{Ph} 2}$ (bis(1methyl-4,5-diphenyl-1H-imidazol-2-yl)methane).

can delocalize through the conjugated NCCCN framework as well as the extended $\pi$-system of the ligand framework.

Herein, we report on a study of homoleptic cobalt(II) complexes derived from deprotonated anionic $\mathrm{BMIM}^{\mathrm{Ph} 2-}$, in which the ligand undergoes facile and reversible redox chemistry. The corresponding zinc(II) complexes were synthesized as diamagnetic analogues, for which the $\mathrm{Zn}^{\prime \prime}$ center $\left(\mathrm{d}^{10}, S=0\right)$ is not expected to participate in redox chemistry and thus, the oxidation state of the ligand is expected to determine the overall charge of the complex. X-ray crystal structure determination, electrochemistry, and various spectroscopic techniques in conjunction with DFT calculations have been employed to elucidate the non-innocent redox character of the $\mathrm{BMIM}^{\mathrm{Ph} 2-}$ ligand in these complexes. These studies establish the $\mathrm{BMIM}^{\mathrm{Ph} 2-}$ ligand as a non-innocent redox NacNac-type ligand in which the non-innocence is no longer "hidden".

Cobalt and zinc complexes were prepared by reacting two equivalents of the anionic ligand with one equivalent of anhydrous metal(II) chloride salt (Scheme 2). The isolated cobalt complex, [Co(BMIM $\left.\left.{ }^{\mathrm{Ph} 2-}\right)_{2}\right]([1 \mathrm{a}])$ has a brown color and is para-
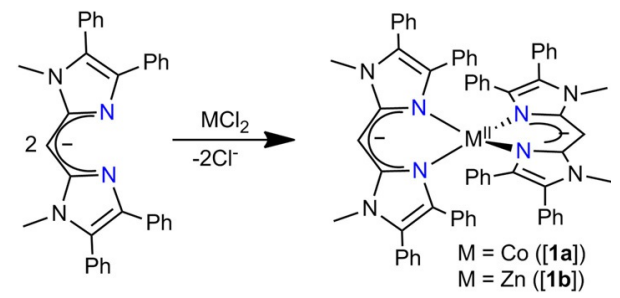

Scheme 2. Synthesis of [1 a] and [1 b] .

magnetic, which is supported by its ${ }^{1} \mathrm{H}$ NMR spectrum (Figure $\mathrm{S} 1$ in the Supporting Information). Solution-state magnetic susceptibility measurements by Evans method confirm that it is a high spin cobalt(II) complex $\left(\mu_{\text {eff }}=3.72 \mu_{B}\right)$. The ESI-MS spectrum of this complex in THF shows an intense peak at 1017.3616 amu (calc'd: $1017.3804 \mathrm{amu}$ ) for [1 a $]^{+}$(Figure S2). The isolated zinc complex $\left[\mathrm{Zn}\left(\mathrm{BMIM}^{\mathrm{Ph} 2-}\right)_{2}\right],[1 \mathbf{b}]$ is yellow and diamagnetic. The ESI-MS spectrum of [1 b] in THF shows an intense peak at 1023.3715 amu (calc'd: $1023.3841 \mathrm{amu}$ ) for [1 b + $\left.\mathrm{H}^{+}\right]^{+}$(Figure S3). This complex shows sharp ${ }^{1} \mathrm{H}$ NMR signals in the normal range for a diamagnetic complex (Figure S4). The central $\mathrm{C}-\mathrm{H}$ proton and the methyl protons appear as singlets at 3.69 and $2.80 \mathrm{ppm}$, respectively. The aromatic proton resonances appear in the range of 7.54-6.83 ppm.
The redox behaviour of cobalt and zinc complexes [1 a] and [1 b] was examined by cyclic voltammetry $(\mathrm{CV})$ in $\mathrm{CH}_{3} \mathrm{CN}$ or THF using TBAPF $_{6}\left(\right.$ TBAPF $_{6}=$ tetrabutylammonium hexafluorophosphate) as supporting electrolyte; all quoted potentials are referenced versus the ferrocene/ferrocenium couple $\left(\mathrm{Fc} / \mathrm{Fc}^{+}\right)$. Cobalt complex [1 a] shows multiple electron-transfer (ET) processes in the potential range of $-3.0 \mathrm{~V}$ to $+1.8 \mathrm{~V}$ in $\mathrm{CH}_{3} \mathrm{CN}$ / TBAPF $_{6}$. This complex features two reversible ET processes at $-0.90 \mathrm{~V}$ and $-0.65 \mathrm{~V}$ along with two quasi-reversible ET processes at $0.34 \mathrm{~V}$ and $0.60 \mathrm{~V}$, respectively (Figure 1). These ET

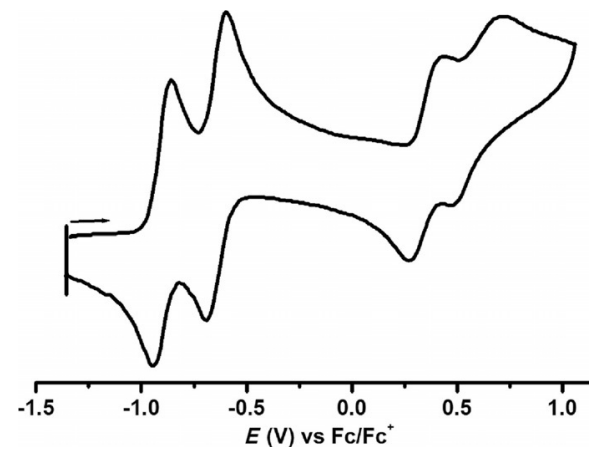

Figure 1. Segmented $\mathrm{CV}$ of complex [1 a] in $\mathrm{CH}_{3} \mathrm{CN} / \mathrm{TBAPF}_{6}$ (scan rate $100 \mathrm{mV} \mathrm{s}^{-1}$ ).

processes are assigned to ligand-centered oxidations on the basis of the similar behaviour of the $\mathrm{Zn}$ analogue [1 b] (vide infra), indicating that the $\mathrm{BMIM}^{\mathrm{Ph} 2-}$ ligand can actually be oxidized twice. An additional, irreversible ET process is noted at $1.21 \mathrm{~V}$ which is assigned to the Co ${ }^{1 / / 11}$ couple (Figure S5 in the Supporting Information).

Zinc complex [1 b] shows three quasi-reversible ET processes at $-0.96 \mathrm{~V},-0.72 \mathrm{~V}$, and $0.30 \mathrm{~V}$ in $\mathrm{THF}^{\mathrm{T}} \mathrm{TBAPF}_{6}$ as shown in Figure S6. The ET process in the anodic region is not well resolved and the peak-to-peak separation is nearly double to what is expected for a one-electron transfer process (Table S1). The peak height of this feature being approximately 2.5 times higher than for the one-electron processes at lower potentials indicates that this feature represents a non-resolved two electron oxidative ET process.

We were able to selectively oxidize the neutral complexes [1 a] and [1 b] at a preparative scale, using either one or two equivalent of $\mathrm{FcBF}_{4}$ as the oxidant (Scheme 3). The one-electron oxidized cobalt complex [2a] $\left(\mathrm{BF}_{4}\right)$ is bright green and absorbs at $640 \mathrm{~nm}$ and $360 \mathrm{~nm}$. The two-electron oxidized cobalt complex $[3 \mathrm{a}]\left(\mathrm{BF}_{4}\right)_{2}$ is intense blue and absorbs strongly at $650 \mathrm{~nm}$

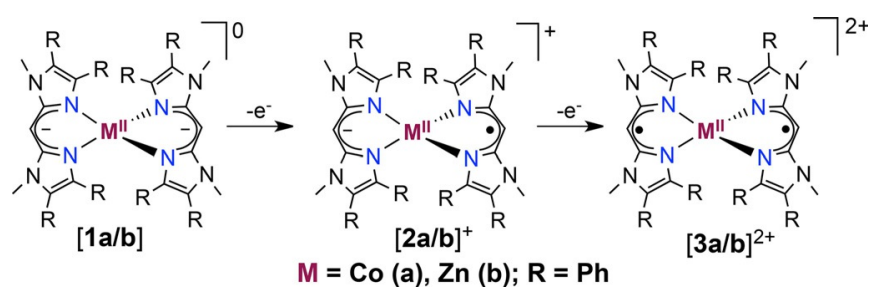

Scheme 3. Synthesis of single and di-oxidized cobalt and zinc complexes. 
(Figure S7 in the Supporting Information). Both the oxidized cobalt complexes are paramagnetic and solution state magnetic moments measured by Evans method indicate the presence of two $\left(\mu_{\text {eff }}=3.12 \mu_{B}\right)$ and one $\left(\mu_{\text {eff }}=1.76 \mu_{\mathrm{B}}\right)$ unpaired spins in $[2 \mathrm{a}]\left(\mathrm{BF}_{4}\right)$ and $[3 \mathrm{a}]\left(\mathrm{BF}_{4}\right)_{2}$, respectively.

The X-band EPR spectrum of the doubly oxidized cobalt complex $[3 \mathrm{a}]\left(\mathrm{BF}_{4}\right)_{2}$ in a frozen dichloromethane-toluene mixture at $100 \mathrm{~K}$ confirms the $S_{\text {tot }}=1 /$ 2 ground state (Figure 2). The simulated spectrum matches with the following $g$ values: $g_{1}=2.720, g_{2}=$ 2.252 , and $g_{3}=2.091 ; g_{\text {iso }}=2.354$, in which $g_{\text {iso }}=$ $\left.\left[\left(g_{1}+g_{2}+g_{3}\right) / 3\right)\right]$. The high ${ }^{[20]} g$ value $\left(g_{\text {iso }}=2.354\right)$ and hyperfine coupling $\left(a_{\mathrm{Co}}=37.5 \times 10^{-4} \mathrm{~cm}^{-1}, 41.9 \times\right.$ $10^{-4} \mathrm{~cm}^{-1}$, and $\left.67.5 \times 10^{-4} \mathrm{~cm}^{-1}\right)$ to the cobalt center

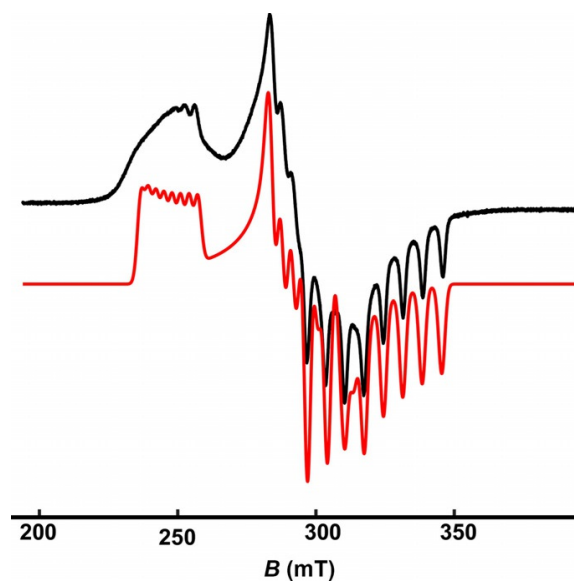

Figure 2. X-band $(9.441 \mathrm{GHz})$ EPR spectrum of the complex $[3 \mathrm{a}]\left(\mathrm{BF}_{4}\right)_{2}$ in dichloromethane-toluene at $100 \mathrm{~K}$ : experimental (black) and simulated (red).

$(I=7 / 2)$ indicate that the unpaired electron is localized on the metal, which is the expected net result of a high-spin Co" center with three unpaired electrons coupled to two ligand radicals. The observed line broadening is due to unresolved Co hyperfine at the higher $g$ values.

The one-electron oxidized zinc complex $[\mathbf{2} \mathbf{b}]\left(\mathrm{BF}_{4}\right)$ turned out to be unstable. We were able to investigate its electronic structure by EPR through its in situ generation upon oxidation with 0.8 equivalent $\mathrm{FcBF}_{4}$. The complex, in a frozen THF-acetonitrile mixture $(5: 1)$ at $100 \mathrm{~K}$, shows a ligand-based single line EPR spectrum at $g=2.003$ with small hyperfine due to coupling with a hydrogen nucleus $\left(a_{\mathrm{H}}=6.96 \times 10^{-4} \mathrm{~cm}^{-1}\right)$ (Figure $\left.3 \mathrm{a}\right)$. The two-electron oxidized zinc complex $[3 \mathrm{~b}]\left(\mathrm{BF}_{4}\right)_{2}$ has a blue color and is thermally unstable. We were able to characterize this complex by UV/Vis and EPR spectroscopy. This complex absorbs at $655 \mathrm{~nm}$ (Figure $\mathrm{S} 8$ in the Supporting Information) and TD-DFT calculations were employed to assign the origin of the electronic transition to intra and inter ligand $\pi \rightarrow \pi^{*}$ transitions (Figure S9 and Table S2). The EPR spectrum recorded in frozen acetonitrile $(100 \mathrm{~K})$ shows a featureless isotropic signal at $g=2.003$ along with a weak half-field $\left(\Delta m_{s}=2\right)$ signal (Figure $3 \mathrm{~b}$ ). The absence of characteristic hyperfine splitting of the partially oxidized zinc complex $[\mathbf{2} \mathbf{b}]\left(\mathrm{BF}_{4}\right)$ and the presence of
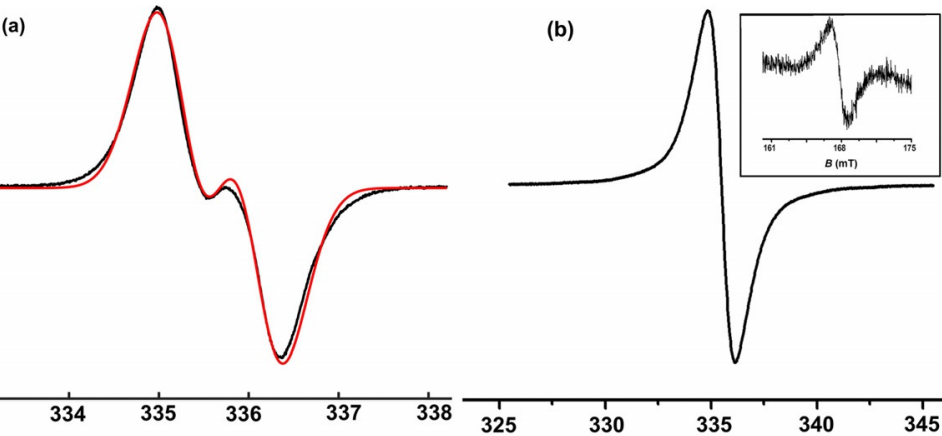

$B(\mathrm{mT})$

325

330

335
$B(\mathrm{mT})$

340

345

gure 3. (a) EPR spectrum of [2 b ] ${ }^{+}$in $\mathrm{THF} / \mathrm{CH}_{3} \mathrm{CN}$ at $100 \mathrm{~K}$ : experimental (black) and simulated (red) (b) EPR spectrum of $[3 \mathbf{b}]^{2+}$ in $\mathrm{CH}_{3} \mathrm{CN}$ at $100 \mathrm{~K}$. Inset: half field signal.

a half-field signal in the EPR spectrum of $[3 \mathbf{b}]\left(\mathrm{BF}_{4}\right)_{2}$ indicate the formation of a triplet di-radical. ${ }^{[9 b, 21]}$ The higher nuclear charge of the $\mathrm{Zn}$ " ion and the lower energies of the $\mathrm{Zn} d$ orbitals may cause less ligand $\pi$-radical-metal covalency, which leads to the instability of the oxidized zinc complexes.

All three cobalt complexes were characterized by X-ray crystal structure determinations. However, we were unable to grow crystals of the zinc complexes due to their thermal instability. All the three cobalt complexes [1a], [2a] $\left(\mathrm{BF}_{4}\right)$, and $[3 \mathrm{a}]\left(\mathrm{BF}_{4}\right)_{2}$ have crystallographic $C_{2}$ symmetry (non-crystallographic $D_{2}$ symmetry), which makes the two ligands within one molecule identical in the crystal. The molecular structure of $[3 \mathrm{a}]^{2+}$ is shown in Figure 4. Molecular plots of [1 a] and $[2 \mathrm{a}]\left(\mathrm{BF}_{4}\right)$ and selected distances and angles of $[\mathbf{1} \mathrm{a}],[2 \mathrm{a}]^{+}$, and $[3 \mathrm{a}]^{2+}$ are submitted in the Supporting Information (Figure S10-11 and Table S3). ${ }^{[22]}$ Due to the high symmetry we did not observe any significant change in the metrical parameters in the singly oxidized cobalt complex, $[2 \mathrm{a}]\left(\mathrm{BF}_{4}\right)$ with respect to

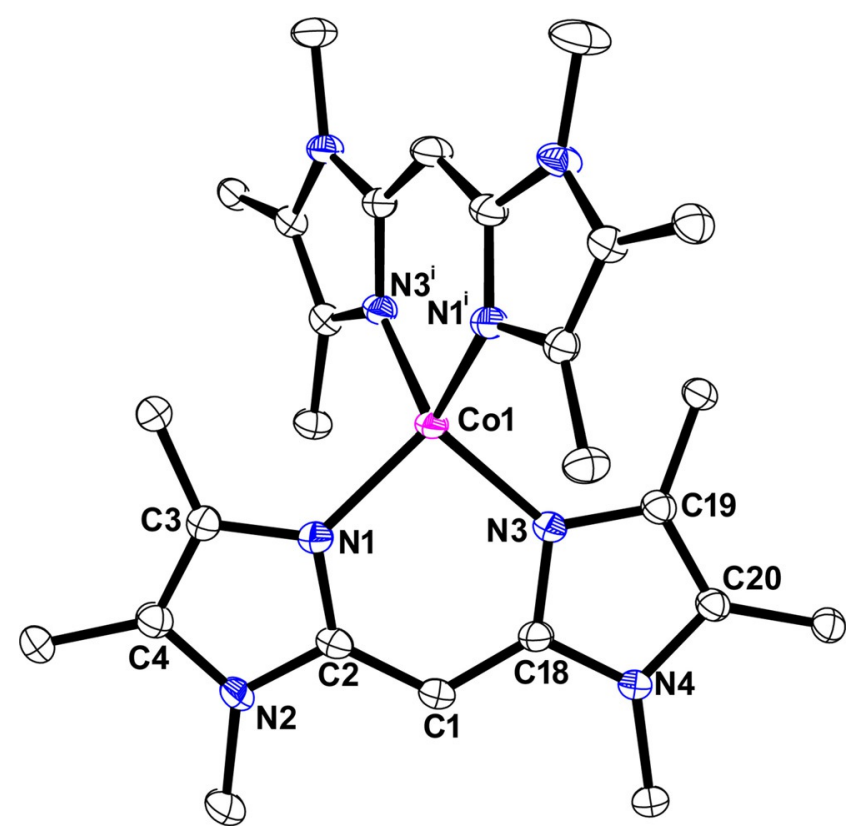

Figure 4. Molecular structure (50\% probability level) and partial atom numbering scheme in complex $[3 \mathrm{a}]^{2+}$. Phenyl rings, hydrogen atoms, counter anions, and solvent molecules are omitted for clarity. 
[1 a] and its structure will not be discussed in detail here. The metrical parameters in the di-oxidized cobalt complex, $[3 \mathrm{a}]\left(\mathrm{BF}_{4}\right)_{2}$ are different from the starting complex, [1 a] and are indicative of the redox non-innocent character of the ligand.

In the crystal, [1 a] has a distorted tetrahedral geometry with

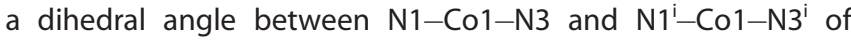
$70.02(9)^{\circ}$. This distortion makes the complex chiral. [1 a] crystallizes as a racemate, $[\mathbf{2}$ a](BF4) as a kryptoracemate with two independent molecules of opposite chirality, and $[3 \mathrm{a}]\left(\mathrm{BF}_{4}\right)_{2}$ as an enantiopure crystal.

The Co-N distances in [1 a] of 1.9916(16) $\AA$ and 1.9944(16) $\AA$ are slightly longer than the reported $\mathrm{Ni}-\mathrm{N}$ distances in $\mathrm{Ni}(\mathrm{Nac}-$ $\mathrm{Nac})_{2}$ complexes. The Co-N distances in $[3 \mathrm{a}]^{2+}$ get $0.019(2)$ and $0.024(2)$ shorter upon oxidation despite the fact that the electron density of the ligands decreases, indicating a stronger bonding interaction between the unpaired electrons on the cobalt center and the $\pi$-ligand radical. The dihedral angle be-

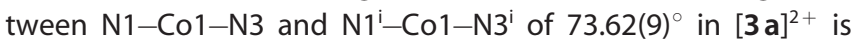
slightly larger than in [1 a]. This structural change around the metal center is consistent with the reported oxidized [Ni(Nac$\left.\mathrm{Nac})_{2}\right]^{+}$system. ${ }^{[19]}$ The distances in [1 a] at the NCCCN backbone are comparable with those in $\mathrm{M}(\mathrm{NacNac})_{2}(\mathrm{M}=\mathrm{Co}, \mathrm{Ni})$. For example, the $\mathrm{C} 1-\mathrm{C} 2$ and $\mathrm{C} 1-\mathrm{C} 18$ distances in [1 a] are 1.400(3) $\AA$ and 1.404(3) $\AA$, whereas these distances are between $1.390-1.409 \AA$ in $\mathrm{M}(\mathrm{NacNac})_{2}(\mathrm{M}=\mathrm{Co}, \mathrm{Ni})$. Upon oxidation, there is no significant change in the NCCCN framework in $\mathrm{M}(\mathrm{NacNac})_{2}$. For example, the contraction and elongation of $\mathrm{C}-\mathrm{C}$ and $\mathrm{C}-\mathrm{N}$ distances upon oxidation in $\mathrm{M}(\mathrm{NacNac})_{2}(\mathrm{M}=\mathrm{Co}$, $\mathrm{Ni})$ are between $0.002-0.009 \AA$ and $0.002-0.008 \AA$, respectively. ${ }^{[18,19]}$ The contraction and elongation of $\mathrm{C}-\mathrm{C}$ and $\mathrm{C}-\mathrm{N}$ distances in the NCCCN framework upon single and double oxidation of [1 a] are also insignificant and comparable with those reported for $\mathrm{M}(\mathrm{NacNac})_{2}$. Significant changes in the metrical parameters are noted though in the substituted $\pi$-systems (imidazole moieties). $\mathrm{N} 1-\mathrm{C} 3$ and $\mathrm{N} 3-\mathrm{C} 19$ distances are 1.401(2) $\AA$ and 1.405(2) $\AA$ in [1 a] and 1.372(2) $\AA$ and 1.369(2) $\AA$ in $[3 \mathrm{a}]^{2+}$. Upon oxidation, these distances are contracted by $0.029(3) \AA$ and $0.036(3) \AA$, respectively. Similarly, $d_{\mathrm{N} 2-\mathrm{C} 4}$ and $d_{\mathrm{N} 4}$ c20 are contracted by $0.025(3) \AA$ and 0.011 (3) $\AA$. The metrical parameter changes in the imidazole moieties make ligand $\mathrm{BMIM}^{\mathrm{Ph} 2-}$ as perceptible non-innocent and shows that the $\pi$ electron is delocalized over the NCCCN backbone and the extended $\pi$-system.

The observation of these structural changes upon oxidation of the ligands in [1 a] is supported by DFT calculations. To examine the electronic structures of the different cobalt and zinc complexes, we have performed a series of calculations using DFT at the B3LYP or M06-HF level as implemented in Gaussian 09. ${ }^{[23]}$ The B3LYP optimized structures of the cobalt complexes are summarized in Table S4 in the Supporting Information. In the case of [1 a] the most stable state is a quartet, consistent with the solution state magnetic data. The Mulliken spin density of 2.64 on the cobalt center is strongly indicative of a highspin Co" configuration and computational analysis therefore supports the Co" oxidation state assignment in complex [1 a] .

The solution state magnetic moment of $[2 \mathrm{a}]\left(\mathrm{BF}_{4}\right)$ indicates the presence of two unpaired spins $(S=1)$ in the molecule.
UB3LYP calculations showed that the $S=1$ ground state is attained by antiferromagnetic coupling of the single delocalized unpaired electron on the ligands $\left(S_{L}=1 / 2\right)$ with one of the three unpaired spins in the $t_{2}$ orbital of the Co" center $\left(S_{C_{0}}=3 /\right.$ 2) (Figure S12). The B3LYP-based spin density plot of $[2 \mathrm{a}]^{+}$indicates that the -1 charge would be delocalized between the two coordinated ligands pointing to a formal charge of -0.5 for each ligand (Figure S12). In general though, the B3LYP functional is known to artificially stabilize delocalized states, ${ }^{[24]}$ which can be solved by using pure HF exchange as in the M06-HF functional. ${ }^{[25]}$ The UM06-HF calculated spin density plot of $[2 \mathrm{a}]^{+}$indeed displays localization of the -1 charge on one ligand only (Figure $5 \mathrm{a}$ ).
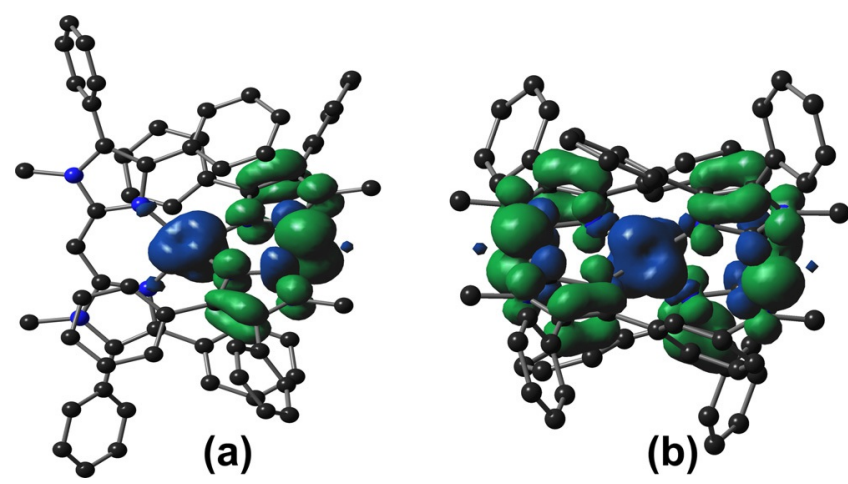

Figure 5. Spin density plot of (a) $[2 \mathrm{a}]^{+}$and (b) $[3 \mathrm{a}]^{2+}$ derived from DFT calculation.

One-electron oxidation of [1 b] yields zinc complex [2 b $]^{+}$, which is found to have its one-electron spin delocalized evenly over both the ligands in the B3LYP optimized structure, whereas the M06-HF optimized geometry again shows a one-electron spin localization over one ligand only (Figure S13). The M06-HF optimized spin density plot is consistent with the experimentally observed hyperfine coupling with a single hydrogen nucleus in the EPR spectrum of $[\mathbf{2} \mathbf{b}]^{+}$. We therefore conclude that the M06-HF functional calculated electronic structure description is better suited to represent the singly oxidized complexes than the B3LYP functional. Based on the EPR of $[\mathbf{2} \mathbf{b}]^{+}$and the absence of a NIR region feature for complex $[2 \mathrm{a}]^{+}$we accordingly propose a localized description of one electron spin on only one ligand in the one-electron oxidized complexes. This situation is in contrast to observations for cationic one-electron oxidized $\beta$-diketiminate cobalt and nickel complexes where one electron spin delocalization over the two ligands was noted, supported by a IVCT (intervalence charge transfer) transition in the NIR region. ${ }^{[17-19]}$

The solution state magnetic moment of $[3 \mathrm{a}]\left(\mathrm{BF}_{4}\right)_{2}$ indicates the presence of a single unpaired electron in the molecule. The broken-symmetry $\mathrm{BS}(3,2)$ calculation and the spin unrestricted $(S=1 / 2)$ calculation for dicationic $[3 a]^{2+}$ were found to be identical. The qualitative MO diagram shows three singly occupied metal $d$ orbitals ( $>85 \%$ ) originating from the central tetrahedral $\mathrm{Co}$ atom. This situation defines a high-spin Co" configuration $\left(S_{C_{0}}=3 / 2\right)$ for the metal center (Figure S14). Two 
metal spins are antiferromagnetically coupled with two $\pi$ ligand radical spins resulting overall in one unpaired spin at the metal center and accordingly a doublet ground state. The calculated Mulliken spin densities shows an $\alpha$-spin density of 2.66 electrons at the Co" center and a net $\beta$-spin density of -1.7 on the two ligands (Figure $5(b)$ ).

For the di-radical zinc complex $[3 \mathbf{b}]^{2+}$ two scenarios were considered: a triplet ground state wherein the two ligand $\pi$ radical electrons are parallel (one on each ligand) and a antiferromagnetically coupled singlet ground state wherein these electrons (one on each ligand) are paired via a superexchange mechanism ${ }^{[26,27]}$ through the metal center (Figure S15). The broken-symmetry singlet di-radical was found to be lower in energy than the triplet di-radical by about $11.7 \mathrm{~cm}^{-1}$, indicating there is little preference between these two states and that these are in equilibrium. ${ }^{[20]}$ Thus, both doubly oxidized di-cationic bis(ligand)-metal complexes are best formulated as $\left[\mathrm{M}\left(\mathrm{BMIM}^{\mathrm{Ph} 2}\right)_{2}\right]^{2+}(\mathrm{M}=\mathrm{Co}, \mathrm{Zn})$ featuring two neutral $\pi$-ligand radicals and a divalent metal center.

The monoanionic $\mathrm{BMIM}^{\mathrm{Ph} 2-}$ ligand has an extended $\pi$ system in addition to the conjugated NCCCN framework that allows for the stabilization of a $\pi$-radical upon oxidation of its metal complexes. Here we showed that upon oxidation $\left(\mathrm{BMIM}^{\mathrm{Ph2}-} \rightarrow \mathrm{BMIM}^{\mathrm{Ph} 2}\right)^{\circ}$ : i) the changes in the intra-ligand distances in the NCCCN backbone ( $\mathrm{C}-\mathrm{C}$ and $\mathrm{C}-\mathrm{N}$ distances) are insignificant, ii) $\mathrm{Co}-\mathrm{N}$ distances are contracted by $\approx 0.02 \AA$, and iii) significant changes occur in the imidazole moieties: upon oxidation $d_{\mathrm{N} 1-\mathrm{C} 3 / \mathrm{N} 3-\mathrm{C} 19}$ and $d_{\mathrm{N} 2-\mathrm{C} 4 / \mathrm{N} 4-\mathrm{C} 20}$ are contracted by $\approx 0.03 \AA$ and $\approx 0.02 \AA$, respectively. Analysis of metrical parameters of the ligand in two-oxidation states, viz. anionic and neutral radical form, clearly reveals that the intra ligand distances depend on its formal oxidation state. This makes $\mathrm{BMIM}^{\mathrm{Ph} 2-}$ a perceptible redox non-innocent ligand. The metrical parameters in this diiminate ligand indicate that the charge is not only localized on the NCCCN backbone but also on the extended imidazole $\pi$ system, which is supported by spin density analysis of the oxidized complexes (Figure 5 and Figure S15) and qualitative molecular orbital (HOMO) analysis of the $\mathrm{BMIM}^{\mathrm{Ph} 2-}$ ligand. The $\mathrm{HOMO}$ of $\mathrm{BMIM}^{\mathrm{Ph} 2-}$ is delocalized over the extended imidazole $\pi$-system in addition to the central carbon atom (Figure S16). The NCCCN frame work comprises two nodes at the imine carbon atoms. Consequently, upon oxidation significant changes of intra-ligand distances are observed in the imidazole moieties.

Electrochemical studies have revealed that the oxidation potentials of homoleptic cobalt and zinc complexes derived from $\mathrm{BMIM}^{\mathrm{Ph} 2-}$ are cathodically shifted compared to other diketiminate complexes. The first oxidation of both ligands in $\left[\mathrm{M}\left(\mathrm{BMIM}^{\mathrm{Ph} 2}\right)_{2}\right](\mathrm{M}=\mathrm{Co}, \mathrm{Zn})$ occurs at potentials that are negative with respect to $\mathrm{Fc} / \mathrm{Fc}^{+}$, thus allowing both anionic ligands to be oxidized using a mild chemical oxidant $\left(\mathrm{FcBF}_{4}\right)$. In comparison, the Co-diketiminate complex [Co(1-mesitylbutane-1,3diimine) ${ }_{2}$ ] reported by Nocera et al. shows only one single-electron oxidative response at $-0.43 \mathrm{~V}$ vs. $\mathrm{Fc} / \mathrm{Fc}^{+},{ }^{[18]}$ whereas cobalt complex $[1 \mathrm{a}]$ reported here shows two single-electron oxidative responses at more negative potentials, viz. -0.90 and -0.64 vs. $\mathrm{Fc} / \mathrm{Fc}^{+}$. Furthermore, the neutral $\pi$ ligand radi- cals in doubly oxidized $[3 \mathrm{a}]^{2+}$ can be oxidized further to their cationic form, as indicated by two additional oxidative singleelectron responses at accessible positive potentials. Investigations on these further oxidations of the complexes are currently ongoing.

In conclusion, we have reported on the redox chemistry of homoleptic Co and $\mathrm{Zn}$ complexes $\left[\mathrm{M}\left(\mathrm{BMIM}^{\mathrm{Ph} 2}\right)_{2}\right]$ derived from a $\beta$-diiminate ligand that is structurally very similar to widely studied $\beta$-diketiminate ligands. These complexes show four reversible/quasi-reversible single-electron oxidations that are all ligand based. The coordinated anionic ligand can thus be oxidized electrochemically by two successive one electron events leading to the successive formation of neutral $\pi$-radical $\left(\mathrm{BMIM}^{\mathrm{Ph} 2}\right.$ ) and cationic (BMIM $\left.{ }^{\mathrm{Ph2}+}\right)$ ligands. The anionic and oxidized $\pi$-radical ligand containing cobalt complexes $[\mathbf{1} a]-[3 a]^{2+}$ and zinc complexes $[\mathbf{1} \mathbf{b}]-[\mathbf{3} \mathbf{b}]^{2+}$ were synthesized and characterized by a number of spectroscopic and computational techniques that corroborated their ligand-based redox chemistry. $X$-ray crystal structure analysis of the cobalt complexes showed that the metrical parameters in the imidazole moieties of the ligand are indicative of its oxidation state, making $\mathrm{BMIM}^{\mathrm{Ph} 2-}$ a "perceptible" non-innocent ligand. These observations are in stark contrast to those for the corresponding cobalt and nickel diketiminate complexes $\left[\mathrm{M}(\mathrm{NacNac})_{2}\right]$, in which the ligand noninnocence is "hidden" and for which so far only singly oxidized complexes have been characterized. Accordingly, $\mathrm{BMIM}^{\mathrm{Ph} 2-}$ and related ligands hold promise as non-innocent ligands in multielectron processes that may or may not involve redox-activity at ligand sites only. Efforts in this area are currently being explored in our laboratory and will be reported in due course.

\section{Acknowledgement}

P.G. acknowledges the European Union for Marie Curie Postdoctoral Fellowship support (H2020-MSCA-IF-2014-657765). M.E.M. thanks the Sectorplan Natuur-en Scheikunde (Tenuretrack grant at Utrecht University) for financial support. The DFT work was carried out on the Dutch national e-infrastructure with the support of the SURF Foundation. The X-ray diffractometer has been financed by the Netherlands Organization for Scientific Research (NWO).

\section{Conflict of interest}

The authors declare no conflict of interest.

Keywords: bis(alkylimidazole)methane - cobalt and zinc complexes $\cdot$ redox noninnocence $\cdot \beta$-diiminate $\cdot \pi$-radical ligand

[1] D. L. J. Broere, R. Plessiusa, J. I. van der Vlugt, Chem. Soc. Rev. 2015, 44, 6886-6915.

[2] O. R. Luca, R. H. Crabtree, Chem. Soc. Rev. 2013, 42, 1440-1459.

[3] V. Lyaskovskyy, B. de Bruin, ACS Catal. 2012, 2, 270-279.

[4] W. I. Dzik, J. I. van der Vlugt, J. N. H. Reek, B. de Bruin, Angew. Chem. Int. Ed. 2011, 50, 3356-3358; Angew. Chem. 2011, 123, 3416-3418.

[5] P. J. Chirik, K. Wieghardt, Science 2010, 327, 794-795. 
[6] H. Grützmacher, Angew. Chem. Int. Ed. 2008, 47, 1814-1818; Angew. Chem. 2008, 120, 1838-1842.

[7] L. Que, W. B. Tolman, Nature 2008, 455, 333-340.

[8] W. Kaim, B. Schwederski, Coord. Chem. Rev. 2010, 254, 1580-1588.

[9] Selected recent example: a) L. A. Berben, B. de Bruin, A. F. Heyduk, Chem. Commun. 2015, 51, 1553-1554; b) M.-C. Chang, T. Dann, D. P. Day, M. Lutz, G. G. Wildgoose, E. Otten, Angew. Chem. Int. Ed. 2014, 53, 4118-4122; Angew. Chem. 2014, 126, 4202-4206; c) W. Kaim, Eur. J. Inorg. Chem. 2012, 343-348; d) S. Samanta, P. Ghosh, S. Goswami, Dalton Trans. 2012, 41, 2213-2226; e) Forum Issue on Redox Noninnocent Ligands: P. J. Chirik, Inorg. Chem. 2011, 50, 9737-9740; f) S. C. Bart K. Chłopek, E. Bill, M. W. Bouwkamp, E. Lobkovsky, F. Neese, K. Wieghardt, P. J. Chirik, J. Am. Chem. Soc. 2006, 128, 13901-13912; g) K. P. Butin, E. K. Beloglazkina, N. V. Zyk, Russ. Chem. Rev. 2005, 74, 531-553 and references therein.

[10] a) J. V. Obligacion, S. P. Semproni, I. Pappas, P. J. Chirik, J. Am. Chem. Soc 2016, 138, 10645-10653; b) C. C. H. Atienza, T. Diao, K. J. Weller, S. A. Nye, K. M. Lewis, J. G. P. Delis, J. L. Boyer, A. K. Roy, P. J. Chirik, J. Am. Chem. Soc. 2014, 136, 12108-12118.

[11] S. Hohloch, B. M. Kriegel, R. G. Bergman, J. Arnold, Dalton Trans. 2016, 45, 15725-15745.

[12] D. Zhu, P. H. M. Budzelaar, Dalton Trans. 2013, 42, $11343-11354$.

[13] Y.-C. Tsai, Coord. Chem. Rev. 2012, 256, $722-758$.

[14] L. Bourget-Merle, M. F. Lappert, J. R. Severn, Chem. Rev. 2002, 102, $3031-3066$.

[15] C. Chen, S. M. Bellows, P. L. Holland, Dalton Trans. 2015, 44, $16654-$ 16670.

[16] C. Camp, J. Arnold, Dalton Trans. 2016, 45, 14462-14498.

[17] M. M. Khusniyarov, E. Bill, T. Weyhermüller, E. Bothe, K. Wieghardt, Angew. Chem. Int. Ed. 2011, 50, 1652-1655; Angew. Chem. 2011, 123, $1690-1693$.

[18] M. P. Marshak, M. B. Chambers, D. G. Nocera, Inorg. Chem. 2012, 51, $11190-11197$.

[19] J. Takaichi, Y. Morimoto, K. Ohkubo, C. Shimokawa, T. Hojo, S. Mori, H. Asahara, H. Sugimoto, N. Fujieda, N. Nishiwaki, S. Fukuzumi, S. Itoh, Inorg. Chem. 2014, 53, 6159-6169.
[20] C. C. Lu, E. Bill, T. Weyhermüller, E. Bothe, K. Wieghardt, Inorg. Chem. 2007, 46, 7880-7889.

[21] M. Abe, Chem. Rev. 2013, 113, $7011-7088$

[22] CCDC 1523161, 1523162 and 1523163 contain the supplementary crystallographic data for this paper. These data can be obtained free of charge from The Cambridge Crystallographic Data Centre.

[23] Gaussian 09, Revision D.01 (2013), M. J. Frisch, G. W. Trucks, H. B. Schlegel, G. E. Scuseria, M. A. Robb, J. R. Cheeseman, G. Scalmani, V. Barone, B. Mennucci, G. A. Petersson, H. Nakatsuji, M. Caricato, X. Li, H. P. Hratchian, A. F. Izmaylov, J. Bloino, G. Zheng, J. L. Sonnenberg, M. Hada, M. Ehara, K. Toyota, R. Fukuda, J. Hasegawa, M. Ishida, T. Nakajima, Y. Honda, O. Kitao, H. Nakai, T. Vreven, J. A. Montgomery, Jr., J. E. Peralta, F. Ogliaro, M. Bearpark, J. J. Heyd, E. Brothers, K. N. Kudin, V. N. Staroverov, T. Keith, R. Kobayashi, J. Normand, K. Raghavachari, A. Rendell, J. C. Burant, S. S. Iyengar, J. Tomasi, M. Cossi, N. Rega, J. M. Millam, M. Klene, J.E. Knox, J. B. Cross, V. Bakken, C. Adamo, J. Jaramillo, R. Gomperts, R. E. Stratmann, O. Yazyev, A. J. Austin, R. Cammi, C. Pomelli, J. W. Ochterski, R. L. Martin, K. Morokuma, V. G. Zakrzewski, G. A. Voth, P. Salvador, J. J. Dannenberg, S. Dapprich, A. D. Daniels, O. Farkas, J. B. Foresman, J. V. Ortiz, J. Cioslowski, D. J. Fox, Gaussian, Inc., Wallingford CT.

[24] a) M. Lundberg, P. E. M. Siegbahn, J. Chem. Phys. 2005, 122, 224103 224109; b) V. M. Geskin, F. C. Grozema, S. D. A. Siebbeles, D. Beljonne, J. L. Brédas, J. Cornil, J. Phys. Chem. B 2005, 109, 20237-20243.

[25] Y. Zhao, D. G. Truhlar, J. Phys. Chem. A 2006, 110, 13126-13130.

[26] D. Herebian, K. E. Wieghardt, F. Neese, J. Am. Chem. Soc. 2003, 125, 10997- 11005.

[27] D. Herebian, E. Bothe, F. Neese, T. Weyhermüller, K. Wieghardt, J. Am. Chem. Soc. 2003, 125, 9116-9128.

Manuscript received: March 17, 2017

Accepted manuscript online: May 23, 2017

Version of record online: June 14, 2017 